\title{
Product layout electronic simulation application to power engineering products design practice based on NX-TeamCenter PLM System
}

\author{
Valeriy Dotsenko ${ }^{1 *}$, Mikhail Serbinovskiy ${ }^{2}$, Anton Priymak $^{2}$, Denis Markelov $^{2}$, and \\ Alexandra Serbinovskaya ${ }^{3}$ \\ ${ }^{1}$ Rostov State Transport University (RSTU), Machine Design Department, 344038; 2 Rostovskogo \\ Strelkovogo Polka Narodnogo Opolcheniya Sq., Rostov-on-Don, Russia \\ ${ }^{2}$ PJSCTKZ «Krasny Kotelshchik», Engineering Directorate, 347928; 220 Lenin St., Taganrog, Russia \\ ${ }^{3}$ Oklahoma State University, 74078; 205 Morrill Hall, Stillwater, OK, USA
}

\begin{abstract}
The article present some issues of product lifecycle support based on Teamcenter and NX software systems as well as the process of product layout electronic simulation application to the design of power engineering products: boilers, heat exchange equipment and nuclear power plants equipment. A comparative analysis of the most popular systems is carried out. Tasks and problems of PLM system implementation and ways to solve them are presented.
\end{abstract}

\section{Introduction}

The creation of computer-aided design (CAD) systems in the world and in Russia in early 1980s gave rise to the development of different design technologies. First CAD drawing packages focused on the products of engineering industry, engineering structures, electric diagrams, etc.; they initially did not allow for special smart features. Later, CAD features have been significantly expanded taking into account the development of PLM system. 1985 saw the beginning of the development and evolution of the system when American Motors Corporation (AMC) formulated the concept of product lifecycle management PLM-system (product lifecycle management), improving the product competitiveness [1, 2]. Product lifecycle management software combines methods and means for the product information support throughout its lifecycle stages. Special features of PLM are to ensure the interaction of various automation means. PLM is the basis integrating informational space, in which CAD, PDM (product data management) and other computer aided systems operate.

Modern market of power boilers is characterized by competition intensification, increased product design, manufacturing and transportation costs. In order to protect their market share, boiler-production companies have to ensure high quality and relatively low cost of their products and services offered. This requires application of new technologies, among which PLM-system plays a significant role. The article presents a model of PLM software systems based on $N X$ -

*Corresponding author: dotsenko_ve@tkz.su 
Teamcenter [3] application at PJSC Taganrog Boiler-Making Works "Krasny Kotelshchik" (hereinafter referred to as TKZ) and its analysis.

The selection of $P L M$-system version had been performed shortly before the system was installed. During the analysis of PLM-systems available at the world market, such systems as Dassault ENOVIA, PTC Windchill [4], Oracle Agile PLM, Omnify Empower PLM, SAP PLM [5], Siemens Teamcenter [6] were considered. The choice was made in favour of Siemens Teamcenter (hereinafter referred to as ST) for the following reasons. ST is a highlevel system, widely employed in Russian engineering companies. ST allows for managing the requirements, projects, engineering processes; product structure, content, documentation, and packaging; preproduction engineering, design data, reports and analytics (collaborative software, embedded visualizer, platform extension services, integration services, and company's knowledge management platforms). The important criterion for the selection of $P L M$-system was the possibility it provides to integrate $C A D / C A M / C A E$ systems in it. NX-Teamcenter software system was chosen as such system.

We should note that the previous analyses of PLM-system implementation for the different companies and research and production complexes of engineering industry showed mixed results due to differences in challenges these companies faced as well as tasks and solutions they implemented. These differences depend, first of all, on the companies' product output type and volume, on the relative share and complexity of design-and-engineering works involved in their production process.

This paper is devoted to the application of $P L M$-system into the manufacturing company's custom-made products for heavy power engineering, i.e. medium- and largecapacity power boilers, heat-exchange equipment and nuclear power plants equipment (NPP). The company is characterized by a large volume of the design-and-engineering works and high complexity process involved in their production process, which involves R\&D. Design and technological engineering constitutes a considerable part of the company's product cost, determines its quality to the great extent, and highly influences the product competitiveness. All these factors directly impact the tasks of PLM-system application, the nature of challenges faced and scope of engineering-related works. The following section of the article describes tasks, challenges and solution for PLM-system application at Engineering Division of a Boiler-Manufacturing Company at the example of TKZ (PJSC TKZ «Krasny Kotelshchik»).

\section{Purposes and Tasks of PLM-System Application at the Boiler- Manufacturing Company}

Similarly to many other companies, application of $N X$-Teamcenter, the product lifecycle support system based on PLM-system, at TKZ has the following purposes: manufacturing time reduction; labour intensity reduction; design, preproduction and production quality improvement due to automation; design processes and preproduction engineering optimization for all types of the products manufactured.

The application of PLM-system based on NX-Teamcenter software system (SS) at TKZ, considering the specifics of the company's operations being custom-made boilers, heatexchange and NPP equipment projects development and manufacturing, has the following tasks:

1) Personnel training at design and process engineering departments to work with $N X$ Teamcenter SS;

2) Implementation of the electronic product layout (EPL) technology to be used during preproduction and production stages as design documentation (DD) originals including the selection and implementation of projects piloting EPL of different types; 
3) Collaborative work management for all the project participants in the current EPL version to exclude collisions during the product manufacturing, to make DD approval process automatic and to manage changes smoothly;

4) Reference data (RD) development;

5) Development of general engineering templates and specific standardized structure components parameterized libraries, different reports, lists and specifications templates to be used at TKZ (Section ARS Reports in Teamcenter);

6) Development of parameterized EPL for boilers and boiler plant parts and assemblies with parameter calculation units for such components as drum, header, piping sections, attachment parts, supports and hangers, heat-exchange parts and other equipment, automatizing data exchange (calculations - development of separate components of a steam boiler or other products - calculations);

7) When forming the product geometry, smooth adjustment of $N X$ calculation module to calculations in other SS;

8) EPL library creation and composition. The library designed and released at TKZ includes a tree of embedded electronic layouts of separate parts, assembly units and spare parts for the whole boiler plant, including heat-exchange equipment or NPP equipment, etc.;

9) Preproduction engineering automation including the parameterized templates and EPL structure members, electronic process documentation, their visual tracking, development and translation of software products for CNC machines;

10) Integration of Teamcenter as part of PLM-system with existing SAP (Systems, Applications and Products in Data Processing) at TKZ.

\section{Discussing Implementation Issues and Their Solutions}

We should note that the specific character of the design and production of the power engineering products, which are manufactured according to individual project requirements in single quantities or small batches in quantity of a few items, determined the difference of purposes and, as a consequence, the problems being solved in the process of PLM-system implementation in TKZ. We shall consider the problems related to each of these tasks and solutions encountered during the system implementation process.

Personnel training problems were connected, at first place, with the complexity of the implemented software; with inability to manage the off-job training of the design and process department personnel, while adhering to the product current engineering and production schedule; and with the fact that none of the training companies were acquainted with the specific character of boilers, heat-exchange products and NPP equipment design and production.

The complexity of the software product required involvement of a third party, which had experience of SS NX-Teamcenter implementation and training. LANIT JSC (AO «ЛАНИТ») (Laboratory of New Information Technologies) [7] was chosen for these purposes. LANIT is a multi-discipline group of IT-companies, one of the leaders of the information technology industry that renders a full range of IT-services. Since 1999, it has been dealing with the implementation of complex PLM systems into industrial enterprises creating complex scientific products of engineering industry. It has implementation experience in Russia with more than 60 enterprises [8]. However, TKZ engineering faced, as stated above, the challenge of the direct training of a large number of TKZ employees by LANIT specialists under the conditions of the product design and manufacture process continuity. Moreover, TKZ has become the first boiler-making company in Russia to implement NX-Teamcenter SS as PLM-system to the full extent using the technology of creating the product electronic layout and the above mentioned specific software products 
"from scratch". LANIT specialists did not know the specific features of the design and manufacturing processes of the boilers, heat-exchange products and NPP equipment under the conditions of the custom engineering and production of the heavy power engineering industry products. Neither were they aware of the large numbers of related calculations and modeling complex and heterogeneous mechanical systems, hydraulic, aerodynamic and heat calculations and their $3 D$ modeling. Despite the fact that $N X$ SS is thoroughly elaborated, it is difficult in training and usage skills development. While some $C A D$ systems are intuitive to learn and develop usage skills, memorizing and repeat action should prevail in learning to use $N X$ SS. Consequently, the training time increases and the necessity of constant consultations grows, which is almost unachievable under the circumstances of a short-term training by a third party.

During the search for solution of these two problems, we adopted two-stage training system for TKZ specialists training. At first, the training was completed by a designated team of TKZ specialists. After that, the specialists, who completed the training, trained other employees of the design and process engineering departments. In this case, we managed to solve the problem of terminology familiarization, specific features of regulatory requirements for the design and production, availability of the required professional skills and experience in boiler-manufacturing.

Implementation of EPL technology into design, carried out by the Engineering Division of TKZ, did not provoke any rejection because similar technology had been earlier implemented as a part of $A V E V A$ SS [9], but it required assimilating the technology to relatively simple products. For this purpose, a number of pilot projects were chosen and executed using EPL technology for the products of different types and separate components of boiler plants, e.g. spray attemperator, economizer coil banks, boiler buckstay fasteners, gas/airducts, and other structure components.

However, significant problems of different character were revealed during the system implementation.

The first group of problems is directly connected with $C A D$-part of the system:

- absence of the system setup for design documentation execution according to Unified System of Design Documentation;

- necessity to design standard and non-standard weld joints;

- problem of "intermediate states" of model creation;

- difference of the designed parts before assembling from their look at a boiler erection site;

- necessity to develop software for geometrical parameters calculation of parts and assembled nodes in accordance with special procedures for integrating their automatic design into the system;

- need to alter the product composition and the assembling elements technology

- absence of notions for non-drawing parts, weld and soldered joints.

Last but not least in this group is the problem connected with the fact that in the conditions of boiler-making production and erection, it is typical not to issue drawings for simple structural components such as for strips of specified length, rectangular plates and other similar parts. In such case, the following is shown in the specification: GOST or TU for the strip, for instance, material, section parameters and the specific length with tolerance, if necessary. The similar description is given for the plates of the required dimensions, parts made of tubes without beveling, standard sections, etc. The system based on $N X$-Teamcenter SS requires performing an electronic drawing for each EPL component including the simplest one. There is a similar problem with the weld joint modeling: $N X \mathrm{SS}$ does not allow for introducing different joints by a description only. Despite the fact that when performing EPL, for example for a weld joint, a template of the weld section geometry is used, it is necessary to simulate its location and length, and for the interrupted 
weld, each section must be positioned in EPL. Consequently, separate software unit for the weld and soldered joints simulation, which allows the designers to add the variables relevant to the weld during the simulation of each joint, was developed for the preproduction engineering automation. The disadvantages of $N X \mathrm{SS}$ are its high labour intensity and unstable operation of the "save" function.

The second group of the problems is connected with the necessity of careful adjustment of NX-Teamcenter communication, including EPL displaying in Teamcenter visualizer, because of the incorrect default display of EPL section in $T C$ visualizer (Fig. 1). When planning system implementation, it is necessary to take into account the importance of the fine tuning of NX-Teamcenter communication, as well as its labour intensity and the necessity to employ highly qualified specialists.

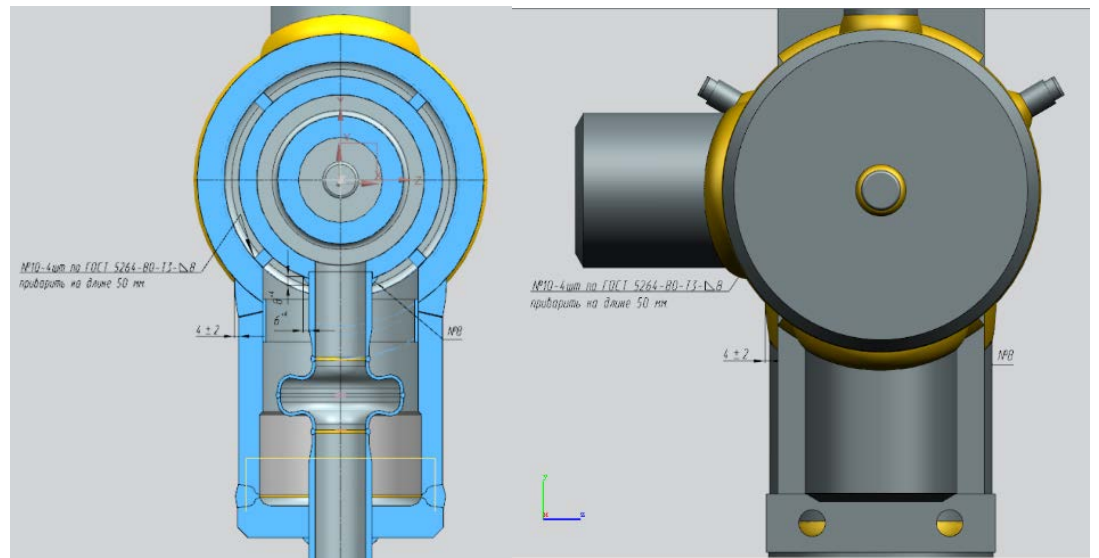

Fig. 1. EPL Section of Header Displayed in $N X$ (left) and in Teamcenter Visualizer (right) without Special Translator Settings.

The third group of the problems is defined by the necessity to review some of the business processes, allocate responsibilities (roles) and implement procedures and regulations for the system operation.

For example, the industry standards for the design documentation development with NX-Teamcenter PLM-system (rules for execution and control of electronic dummies of the parts and assembly units, engineering in the scope of a product, procedures for test structure operation, etc.) were developed and implemented at PJSC TKZ "Krasny Kotelshchik". The procedure of elements formation and presentation to describe various protecting coating schemes for parts and assembly units, specified in the industry standard, was implemented. The following special tools were developed: «Registry Books» and «Log-Book for Comments».

The stage of reference databases creation and the required sections of the libraries creation for general engineering and specific normalized components of the structures for the purposes of engineering assurance is complicated and labor-intensive, that is why this stage was started at the same time with the decision made about on PLM-system of $N X$ Teamcenter implementation. In this case, "from simple-to-complex" method was used. First of all, the reference databases and libraries of standardized and standard parts were created. Then, the development of structural components for assembly units followed. Such method is justified, first of all, because the standardized and standard parts are constantly used by the designers, and EPL assembly reference frequency is considerably lower; secondly, the designers have gradually been accumulating skills to work with the structure components of higher complexity.

Similar method was used for more complex layout development of parameterized EPL for the parts and assembly units with the parameter calculation for the boilers and boiler 
plant components, e.g. drum, header, pipeline sections, attachments, supports and hangers, heat-exchange parts and other equipment and the data exchange automation (calculations development of separate components of a steam boiler or of other product - calculations).

It should be noted that the practice of PLM-system implementation revealed that the adjustment of the $N X$ calculation unit and calculations in other SS during the product geometry development cannot be performed by a third party specialists and require engagement of TKZ highly qualified employees (designers, estimators and programmers), who know the specific character of TKZ design work; such adjustment is quite difficult and labour-intensive. In view of the above, these works were performed at TKZ Engineering Division for the separate projects. It should be additionally noted that the creation of the parameterized EPL library required the development of individual procedures, algorithms and calculation programs for the specific assembly units and structure components of TKZ products.

During creation and completing of EPL library sections for the corresponding field of the boiler plants, heat-exchange equipment and NPP equipment, TKZ highly qualified designers and estimators involvement is highly required. The layouts, including the layouts of the parameterized standardized and standard structure components, shall automatically and constantly be used in the future engineering, that is why the mistakes of the structures and preset calculations may be replicated and decrease the safety and competitiveness of the production.

The same is true about preproduction engineering automation when parameterized templates and EPL structure components are used. Their qualified and thorough technological analysis is required in order to eliminate possible losses at the stage of production. Execution of electronic documents and development of software of CNC production centers requires high quality training for preproduction engineering and manufacturing process specialists, as well as experience in $P L M$-system tools program use.

Ensuring the visual displaying and translation of $\mathrm{CNC}$ production center software must comprise the stage of the special careful system adjustment for needs of a specific production taking into account the specific character of the products.

It also needs to be noted that Teamcenter as a part of PLM-system integration with the existing SAP-system at TKZ will only be relevant to companies currently working with $S A P$-system. At TKZ such system was installed a relatively long time ago, and a number of design and engineering documents, e.g. product material specifications, are used in it as a part of planning and accounting tasks in the end-to-end design and production. Hence, it is necessity to use similar documents located in Teamcenter SS libraries with their proper transfer into SAP. At present, the company is working at the transfer process improvement.

\section{Conclusions}

1. The implementation tasks of PLM-system on the basis of NX-Teamcenter SS are described and classified at the example of Engineering Division of PJSC TKZ "Krasny Kotelshchik". The described tasks can be relevant to other machine-building companies.

2. The issues identified and solutions implemented in the process of SS application and implementation, in respect to each task completed, are presented.

3. As described, efficiency improvement, time reduction and design-engineers, estimators, designers and preproduction engineering specialists training quality increase require two-stage training: first stage training of a small group of engineering specialists organized by a specialized training company; at the second stage, the trained specialists become trainers and consultants for all other Engineering Division employees during the whole implementation period. 
4. The conversion to EPL technology is labour consuming, requires engineering process rethinking, engagement of the most qualified Engineering Division employees, careful adjustment of the whole software system with respect to the specifics of the company and expansion of its functional characteristics. PLM-system performance effectiveness depends directly on the quality of the preparation stage of its application.

5. In general, PLM-system based on NX-Teamcenter SS has the following disadvantages: it requires a long-term engagement of highly professional engineering specialists during the implementation process at the most stages of it and this will not produce any results without the detailed addressing of the issues arising in the process of the training. However, in case of successful implementation, it takes the company to a new level of design documentation and all developed products management, ensuring the manufacturing of high-quality products with engineering and production costs reduction.

\section{References}

1. Product lifecycle, https://ru.qwe.wiki/wiki/Product_lifecycle (retrieval date: 10.02.2020)

2. S. Hill, Jr., How To Be A Trendsetter: Dassault And IBM PLM Customers Swap Tales From The PLM Front, https://web.archive.org/web/20090213042744/http://www.coe.org/coldfusion/newsnet/ may03/technology.cfm (retrieval date: 10.02.2020)

3. LANIT Intellectual Engineering in active service for Power Machines, http://cadcamcae.lv/N113/06-22.pdf (retrieval date: 10.02.2020)

4. About Windchi, https://www.ptc.com/en/products/windchill (retrieval date: 10.02.2020)

5. $R \& D$ Engineering, https://www.sap.com/products/digital-supply-chain/plm-r-dengineering.html (retrieval date: 10.02.2020)

6. Teamcenter, https://www.plm.automation.siemens.com/global/ru/products/teamcenter/ (accessed date: 10.02.2020)

7. LANIT Corporate Group, http://www.plmlanit.ru/about/lanit (retrieval date: 10.02.2020)

8. List of JSC LANIT Customers, http://www.plmlanit.ru/projects/customers (retrieval date: 20.03.2020)

9. N. Artamonova, SAPR and Graphics, A new age for the technologies of design, 11 (2012), https://sapr.ru/article/23425 (retrieval date: 20.03.2020) 